Document downloaded from:

http://hdl.handle.net/10251/79779

This paper must be cited as:

López-De-Dicastillo, C.; Catala Moragrega, R.; Gavara Clemente, R.; Hernandez Muñoz, MP. (2011). Food applications of active packaging EVOH films containing cyclodextrins for the preferential scavenging of undesirable compounds. Journal of Food Engineering. 104(3):380-386. doi:10.1016/j.jfoodeng.2010.12.033.

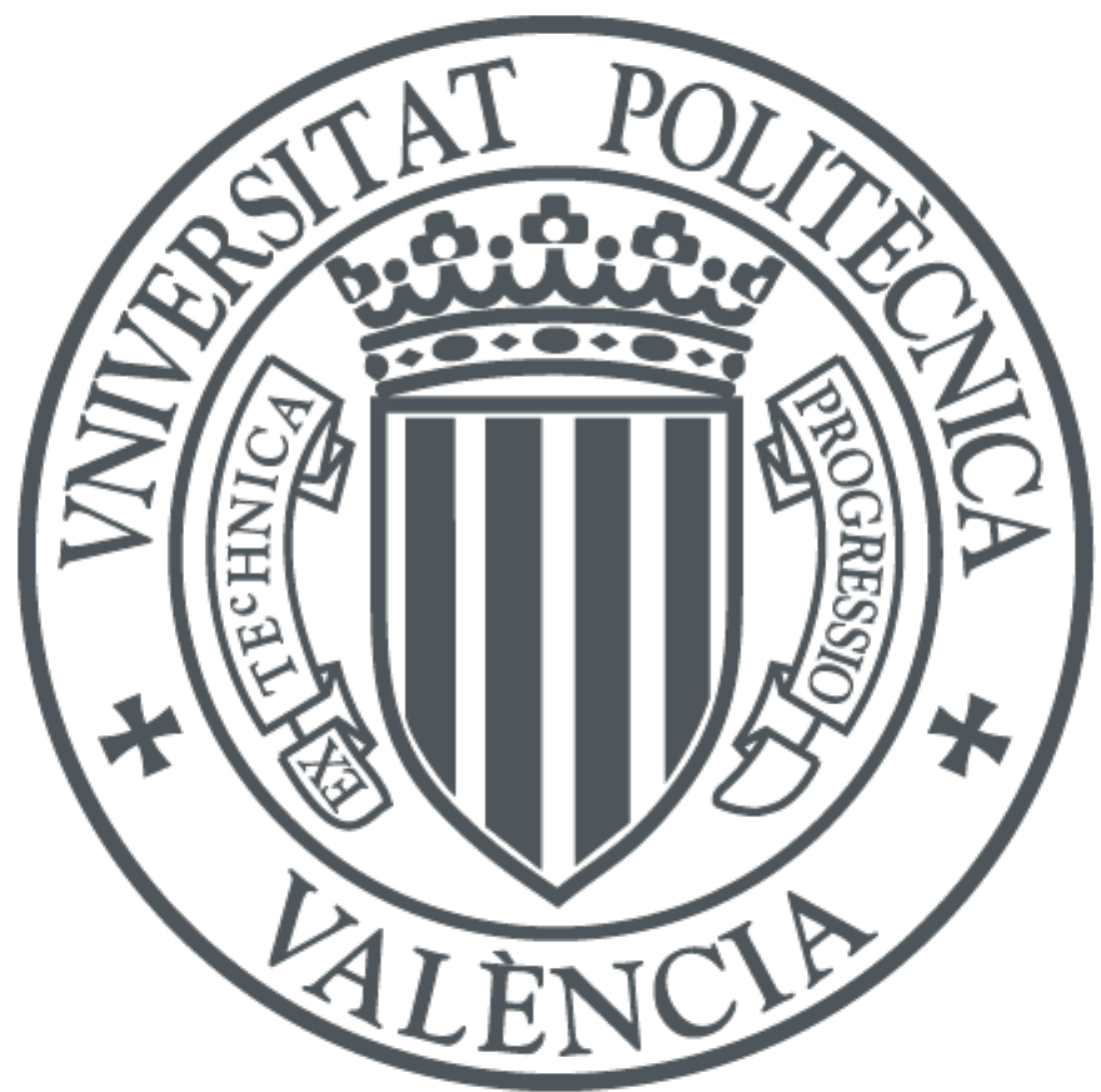

The final publication is available at

http://dx.doi.org/10.1016/j.jfoodeng.2010.12.033

Copyright Elsevier

Additional Information 


\section{Food applications of active packaging EVOH films containing cyclodextrins for the preferential scavenging of undesirable compounds}

Article in Journal of Food Engineering · June 2011

DOI: 10.1016/j.jfoodeng.2010.12.033

CITATIONS

25

4 authors, including:

\section{Carol Lopez de Dicastillo}

University of Santiago, Chile

30 PUBLICATIONS 453 CITATIONS

SEE PROFILE
READS

43

\section{Ramon Catala}

Spanish National Research Council

69 PUBLICATIONS 1,495 CITATIONS

SEE PROFILE

Some of the authors of this publication are also working on these related projects:

Project

Nanoreinforced PLA materials through the incorporation of cellulose nanowhiskers into electrospun fiber matrixes View project

Aplicación de extractos naturales de plantas autóctonas chilenas en el desarrollo de envases activos con capacidad antioxidante y antimicrobiana" View project 

cyclodextrins for the preferential scavenging of undesirable compounds

Carol López-de-Dicastillo, Ramón Catalá, Rafael Gavara* and Pilar Hernández-Muñoz

8

* Corresponding author

Abstract

Novel ethylene-vinyl alcohol copolymer (EVOH) films containing beta-cyclodextrins $(\beta C D)$ with potential application in active food packaging have been tested as materials for the preferential retention of undesired food components. The films were immersed on pasteurized milk and UHT milk and stored at 4 and $23^{\circ} \mathrm{C}$, respectively. The films containing $\beta C D$ presented a significant reduction in cholesterol concentration, achieving a $23 \%$ reduction in UHT milk exposed to EVOH films containing 30\% $\beta C D$. Despite the immobilization of the $\beta C D$ and the large molecular size of cholesterol, $15 \%$ of the $\beta C D$ molecules added to the films were involved in the formation of $\beta C D /$ cholesterol inclusion complexes. In another set of experiments, the films were used to reduce the presence of aldehydes (substances which develop as a result of oxidative processes) in packaged fried peanuts. The films containing $\beta C D$ brought a significant reduction in hexanal, reaching a 50\% decrease over short periods (1-5 weeks). At longer storage times (10 weeks) the retention capacity of the developed films was exhausted and no differences were observed between the samples.

Keywords: active packaging; cyclodextrins; EVOH; cholesterol scavenging; aldehydes retention; lipid oxidation 


\section{Introduction}

Active packaging is one of the emerging technologies which is being developed as an alternative to traditional food processing (intense heat treatments, salting, acidification, drying and chemical preservation). Active packaging does more than simply provide a barrier to external detrimental factors, as the packaging system plays an active role in food preservation and quality during the marketing process (López-Rubio et al., 2004). Active packaging materials are designed to deliberately incorporate components that release or absorb substances into or from the packaged food or the environment surrounding the food to extend the shelf-life or to maintain or improve the condition of the packaged food (Regulation (CE) No 450/2009 (29/05/2009)). Nowadays, active material developments are focusing on polymeric matrices which release active agents (antimicrobials, antioxidants, etc.) and/or retain substances such as oxygen, ethylene or water (Charles et al., 2006; Flores et al., 2007) or undesired food components. While the scavengers used in the latter applications are mainly based on inorganic metals or salts, which have mechanisms of action based on irreversible reactions, the present work studies the use of cyclodextrins as potential scavengers.

Beta-cyclodextrin $(\beta C D)$ is an inexpensive enzyme-modified starch derivative, composed of seven glucose units linked by $\alpha(1 \rightarrow 4)$ glycosidic bonds in a cylindrically shaped cavity with a hydrophobic inner surface and a hydrophilic outer surface. The hydrophobic cavity is able to form inclusion complexes with a wide range of organic guest molecules principally by means of weak forces, such as van der Waals, dipoledipole interactions, and hydrogen bonding. The use of cyclodextrins has increased annually in the food sector (Astray et al., 2009) mainly to remove cholesterol but also as carriers for molecular encapsulation of flavors and other sensitive ingredients. Several reviews have been published describing their possible applications in food processing and as food additives with different aims (Cravotto et al., 2006), although their use is mainly based on the direct addition of the oligosaccharides to the liquid food, and precipitation and separation of the resulting inclusion complexes. In this work, the retention capacity of $\beta C D$ immobilized in packaging structures is explored. 
complexation ratios ranging from 1:1 to 1:3 (Yamamoto et al., 2005). The main driving force for complex formation is the release of enthalpy-rich water molecules from the cavity. Water molecules are displaced by more hydrophobic guest molecules present in the solution to attain an apolar-apolar association and a decrease of cyclodextrin ring strain resulting in a more stable lower energy state. Cholesterol has already been removed from milk and dairy products by a $\beta C D$-based process, and the resulting lowcholesterol butter and cheese are indistinguishable from untreated products (Schroder \& Baer, 1990).

Complexation with a wide range of organic molecules has already been researched and demonstrated. Cyclodextrins (CDs) have been used to retain and/or release volatile compounds, such as aromes, aldehydes, ketones, etc (Almenar et al., 2007, Szejtli, 1982). Previous analysis showed that complexation is related to the polarity of substances, the most apolar compounds having the highest complexation values (López de Dicastillo et al., 2010). Lipid oxidation of stored peanuts leads indirectly to the formation of aliphatic aldehydes, ketones and alcohols, (Burroni et al., 1997; Wambura and Yang, 2010; Williams et al., 2006). Lipids are the major components in peanuts, where approximately $80 \%$ are unsaturated. Oxidation products and rancid flavors decrease the sensory quality of peanut products at very low concentrations, making them unacceptable to consumers, even before the end of their shelf life.

In a previous work (López de Dicastillo et al., 2010), different concentrations $\beta(C D$ were incorporated by extrusion into a hydrophilic ethylene-vinyl alcohol copolymer (EVOH). The films obtained, when exposed to a mixture of organic compounds, presented preferential sorption capacity for apolar compounds. The aim of this work was to use these materials with real food products to reduce the levels of undesired components. Concretely, the films were used to scavenge undesired compounds through the formation of inclusion complexes: a) reducing the cholesterol content of milk by direct contact of the food product with the packaging films, and b) reducing the oxidation byproducts in the package headspace of fried peanuts.

\section{Materials and methods}

\subsection{Chemicals and reagents}


104 The ethylene vinyl alcohol copolymer with a 44\% ethylene molar content (EVOH) was

105 kindly supplied by The Nippon Synthetic Chemical Company, (Osaka, Japan). $\beta C D$ was 106 obtained from Wacker Ibérica (Barcelona, Spain), glycerol from Sigma (Madrid, Spain) 107 and, cholesterol, 5 $\alpha$-cholestane and potassium hydroxide from Fluka Biochemika 108 (Barcelona, Spain). Hexane and methanol were from Merck (Barcelona, Spain) and 109 pentanal, hexanal, heptanal, 2-heptenal, octanal, and 2-octenal from Sigma (Madrid, 110 Spain). Molecular weights and sizes of $\beta C D$ cyclodextrins, cholesterol and selected 111 aldehydes have been included in Table 1.

113 Table 1. Physicochemical characteristics of cyclodextrins and undesirable compounds.

\begin{tabular}{|c|c|c|c|}
\hline Compound & $\begin{array}{c}\text { MW } \\
(\mathrm{g} / \mathrm{mol}) \\
\end{array}$ & $\begin{array}{c}\text { Volume } \\
\text { (§̊) }\end{array}$ & $\begin{array}{c}\text { Diameter } \\
(\AA) \\
\end{array}$ \\
\hline cholesterol & 386.65 & 428.11 & 8.08 \\
\hline cholesterol tail*1 $^{1}$ & 113.23 & 147.29 & 5.42 \\
\hline pentanal & 86.13 & 98.43 & 4.88 \\
\hline hexanal & 100.16 & 115.41 & 5.23 \\
\hline heptanal & 114.18 & 132.41 & 5.04 \\
\hline 2-heptenal & 112.17 & 124.70 & 5.67 \\
\hline octanal & 128.21 & 149.40 & 5.15 \\
\hline 2-octenal & 126.10 & 141.67 & 5.58 \\
\hline$\beta$-cyclodextrin $*^{2}$ & 1135.00 & 262.00 & $6.00-6.50$ \\
\hline
\end{tabular}

117 Water was treated by a Milli-Q Plus purification system (Millipore, Molsheim, France).

118 Hacendado $^{\mathrm{TM}}$ fried peanuts and pasteurized whole milk and UHT whole milk were 119 acquired from a local supermarket (Mercadona, Valencia, Spain).

\subsection{Film preparation}

$123 \beta$-cyclodextrins were incorporated at two different concentrations (20 and 30\% w/w)

124 into the hydrophilic EVOH material by flat extrusion. Polymer pellets were previously 125 dried during two days at $60{ }^{\circ} \mathrm{C}$ under vacuum. In a previous trial, the direct addition of $126 \beta C D$ into the extruder hopper produced very deficient films with holes and $\beta C D$ 127 agglomerates and a poor distribution of the oligosaccharides. For this reason, a glycerol$128 \beta C D$ 1:1 (w:w) paste was prepared, mixed with the polymer pellets, and melt blended 
129 during extrusion in a Brabender DSE 20/40 co-rotating twin screw extruder

130 (Plastograph, Dusseldorf, Germany) with a screw speed of $100 \mathrm{rpm}$ and with the

131 following thermal profile: $160{ }^{\circ} \mathrm{C}, 180^{\circ} \mathrm{C}, 200{ }^{\circ} \mathrm{C}, 190{ }^{\circ} \mathrm{C}$ in the barrel and $190{ }^{\circ} \mathrm{C}$ at the

132 flat die. The addition of glycerol improved the miscibility of the $\beta C D$ and the polymer

133 during the extrusion process and a more homogeneous distribution of the

134 oligosaccharide was achieved The resulting films were ca. $50 \mu \mathrm{m}$ thick, although the

135 thickness of every sample was individually measured with a digital Mitutoyo

136 micrometer (Metrotec, San Sebastian, Spain) at 10 positions in the measured area before

137 conducting the experiments.

138 To avoid contaminations, film samples were vacuum-packed in aluminum/LDPE bags

139 and stored at room temperature until the moment of analysis.

140

141 The transparency of the films was determined through the surface reflectance spectra in 142 a spectrocolorimeter CM-3500d (Minolta Co, Tokyo, Japan) with a $30 \mathrm{~mm}$ illuminated

143 sample area. Measurements were taken from three samples in each formulation by using 144 both a white and a black background. The transparency was determined by applying the 145 Kubelka-Munk theory for multiple scattering to the reflection spectra. As each light 146 flux passes through the layer, it is affected by the absorption coefficient $(K)$ and the 147 scattering coefficient $(S)$. Transparency $(K / S)$ was calculated, as indicated by Hutchings 148 (1999), from the reflectance of the sample layer on a known reflectance background and 149 on an ideal black background. Also, the internal transmittance was evaluated. Further 150 details on the procedure can be found in Fabra et al. (2010).

151

152

\subsection{Cholesterol in milk}

153

154

\subsubsection{Milk sample preparation}

155 In the present work, prior to any test, the film samples were immersed in water under 156 agitation for 24 hours, to eliminate any polymer residues (including cyclodextrins) 157 which could migrate out of the film, and then dried with a tissue paper and subsequently 158 in a vacuum oven at $40^{\circ} \mathrm{C}$ for 24 hours. This way, no retention or scavenging could be 159 attributed to inclusion complexes formed outside of the active film. 
161 To simulate the conditions of a conventional package for pasteurized whole milk, a

162 piece of film was placed in contact with real milk at a surface/volume ratio equivalent to that of a $1 \mathrm{~L}$ carton.

After sterilizing the film surfaces by UV irradiation for $15 \mathrm{~min}$, approximately $12.8 \mathrm{~cm}^{2}$ of each of the films were immersed in $20 \mathrm{~mL}$ of pasteurized whole milk and kept at $4{ }^{\circ} \mathrm{C}$ for one week in a closed vial covered by aluminum foil to avoid any potential effect of 168 light.

In a second experiment, the UV irradiated film samples were immersed in $20 \mathrm{~mL}$ of UHT whole milk and kept at $23{ }^{\circ} \mathrm{C}$ for one week. In this experiment, the milk package, films, vials and milk were handled under sterile conditions to prevent the risk of bacterial contamination and milk spoilage. The experiments were carried out in quintuplicate.

\subsubsection{Cholesterol determination}

The determination of cholesterol in milk was carried out by a simple and rapid method based on direct saponification of the samples with methanolic $\mathrm{KOH}$ solution (Fletouris et al., 1998). A $0.3 \mathrm{~g}$ sample of milk was accurately weighed into a sample preparation vial and $5 \mathrm{~mL}$ of $0.5 \mathrm{M} \mathrm{KOH}$ methanolic solution were added, followed by $40 \mu \mathrm{L}$ of a hexanolic solution of $5 \alpha$-cholestane $1 \mathrm{mg} / \mathrm{mL}$ as the internal standard. The vial was closed tightly and vortexed for $15 \mathrm{~s}$. The vial was then immersed in a $75{ }^{\circ} \mathrm{C}$ bath under agitation for $25 \mathrm{~min}$. Several vials with different samples could be handled conveniently by placing them in a wire basket. Following heating, the vials were cooled to room temperature, $1 \mathrm{~mL}$ of water and $5 \mathrm{~mL}$ of hexane were added, and the contents were vortexed vigorously for $1 \mathrm{~min}$ and then centrifuged for $3 \mathrm{~min}$ at $1500 \mathrm{rpm}$. An aliquot of the upper phase was injected for GC analysis.

The cholesterol concentration was determined in a fused capillary column (30 m x 0.22 mm x $0.22 \mu \mathrm{m}$ ) model TRB-STEROL (Teknokroma S. Coop. C. Ltda., Barcelona, Spain) using an HP 5890 gas chromatograph (Agilent Technologies, Barcelona, Spain) equipped with a flame ionization detector. The chromatographic conditions were as follows: He carrier gas, $4 \mu \mathrm{L}$ sample injection volume, 1/20 split ratio, isothermal 
running at $285{ }^{\circ} \mathrm{C}$ for 15 minutes, injection port temperature $300{ }^{\circ} \mathrm{C}$, and flame ionization detector temperature $300{ }^{\circ} \mathrm{C}$. The cholesterol was quantified through a 5 point calibration curve with $5 \alpha$-cholestane as the internal standard. A linear peak area/concentration response $(r=0.998)$ was observed within the tested range (1-300 $\mathrm{mg} / \mathrm{L})$. The analysis was carried out in triplicate and the cholesterol in the control/blank samples was determined for each batch of test samples. The results are expressed as the average \pm standard deviation concentration (w/v).

\subsection{Monitoring oxidation by-products from fried peanuts}

$25 \mathrm{~g}$ of fried peanuts and a $10 \mathrm{~cm}$ x $8 \mathrm{~cm}$ piece of the developed films were placed in a $100 \mathrm{~mL}$ glass vial, hermetically closed with a twist-off closure equipped with a sampling port, and stored at $37{ }^{\circ} \mathrm{C}$ for 10 weeks. Vials with no material, named "peanut", and with EVOH without cyclodextrins, named "blank", were prepared in order to check the scalping activity of the pure EVOH copolymer. The tests were carried out in quintuplicate.

The organic compounds retention of the different films was quantified by gas chromatography with flame ionization detection (GC-FID) at intervals throughout the storage time. A Supelco 65- $\mu \mathrm{m}$ DVB/PDMS solid phase micro extraction (SPME) fiber (Teknokroma, Barcelona, Spain) was exposed to the vial headspace for $45 \mathrm{~min}$ and immediately desorbed for $10 \mathrm{~min}$ in the injector of an HP5890 gas chromatography (Agilent Technologies, Barcelona, Spain) equipped with a $30 \mathrm{~m}, 0.32 \mathrm{~mm}, 0.25 \mu \mathrm{m}$ TRB-MetaX5 capillary column (Teknokroma, Barcelona, Spain). The chromatographic conditions were as follows: He as the carrier gas, splitless injection, $210{ }^{\circ} \mathrm{C}$ and $300{ }^{\circ} \mathrm{C}$ injector and detector temperatures, $5 \mathrm{~min}$ at $40{ }^{\circ} \mathrm{C}$, first heating ramp to $60{ }^{\circ} \mathrm{C}$ at 3 ${ }^{\circ} \mathrm{C} / \mathrm{min}$, second heating ramp to $200{ }^{\circ} \mathrm{C}$ at $10{ }^{\circ} \mathrm{C} / \mathrm{min}$, and $5 \mathrm{~min}$ at $200{ }^{\circ} \mathrm{C}$.

The volatile compounds were identified in an HP 5890 series II gas chromatograph equipped with an HP 5972 mass-selective detector. The compounds adsorbed by the fibre were desorbed in the injection port of the GC-MS for $10 \mathrm{~min}$ at $210{ }^{\circ} \mathrm{C}$ with the purge valve off (splitless mode). The compounds were separated in a $30 \mathrm{~m}, 0.32 \mathrm{~mm}$, $0.25 \mu \mathrm{m}$ TRB-5MS capillary column (Teknokroma, Barcelona, Spain) with the same conditions as in the GC-FID analysis. The compounds were identified by comparison 
with mass spectra from the library database (NIST 98), and by comparison with authentic standards in both GC-MS and GC-FID. No calibration curves were constructed; therefore the results are expressed as peak area units.

232

233 The aldehyde uptake was analyzed with a Dynatherm Thermal Desorber (Supelco, 234 Teknokroma, Spain) connected in series to the column of an HP5890 gas 235 chromatograph (Agilent Technologies, Barcelona, Spain) via a heated transfer line. At 236 the end of the storage time, a cut piece of the film was inserted into an empty desorption 237 tube. The tube was placed in the desorber chamber, which was immediately sealed. The desorption conditions were: desorption temperature $180{ }^{\circ} \mathrm{C}$, transfer line $180{ }^{\circ} \mathrm{C}$, desorption time $300 \mathrm{~s}$. The GC was equipped with a TRB5 (30 m, $0.32 \mathrm{~mm}, 0.25 \mu \mathrm{m})$ column (Teknokroma, Barcelona, Spain) and a flame ionization detector. After the analysis, the film sample was recovered from the desorption tube and weighed on an analytical balance. The Desorber-GC was calibrated by measuring film samples with known amounts of each aroma (measured independently by gravimetry).

\subsection{Statistical analysis}

246 One-way analyses of variance were carried out using the SPSS computer program (SPSS Inc., Chicago, IL, USA). Differences in pairs of mean values were evaluated by the Tukey-b test for a confidence interval of $95 \%$. The data are represented as average \pm standard deviations.

250

\section{Results and discussion}

252

253 In a previous characterization study of EVOH films containing beta-cyclodextrin the 254 level of immobilization was measured by determining the global migration values of the polymer into water (Lopez de Dicastillo et al., 2010). This analysis revealed that films with $20 \%$ and $30 \%$ of cyclodextrins released approximately $12 \%$ and $14 \%$ of their weight respectively after one day's immersion in water. Similar values were measured after ten days of storage, indicating a non-diffusion controlled migration process. Since the release of glycerol in the control samples was below $2 \%$, approximately $10 \%$ and $18 \%$ of $\beta C D$ are actually immobilized in the EVOH film matrix. Film transparency was evaluated through the Kubelka-Munk K/S coefficient, defined as the ratio between light 
262 absorption and scattering and the internal transmittance of the film (Ti). An increase in

$263 \mathrm{~K} / \mathrm{S}$ or Ti can be assumed as an increase in transparency.

264 Figure 1 shows the profile of K/S and internal transmittance values as a function of 265 wavelength. As it can be seen, the addition of glycerol reduced the transparency of the 266 film, especially at the lower wavelengths. The incorporation of cyclodextrins results is a 267 slight decrease in the values of K/S that increases with the wavelengths. This result 268 appears to indicate that the presence of the cyclodextrins in the matrix reduces 269 transparency by increasing light scattering. Nevertheless, this decrease is not so relevant 270 when expressed as internal transmittance. Ti values for pure EVOH and EVOH-glycerol

271 films are well above $80 \%$ transmittance throughout all the spectra. The incorporation of $27220-30 \%$ of cyclodextrins reduced the transmittance in a $10 \%$ at any wavelength. 273 Therefore, the application of the active EVOH-based layer to the packaging structure 274 will imply a reduction in transparency, which will be less noticeable with the reduction 275 of layer thickness.
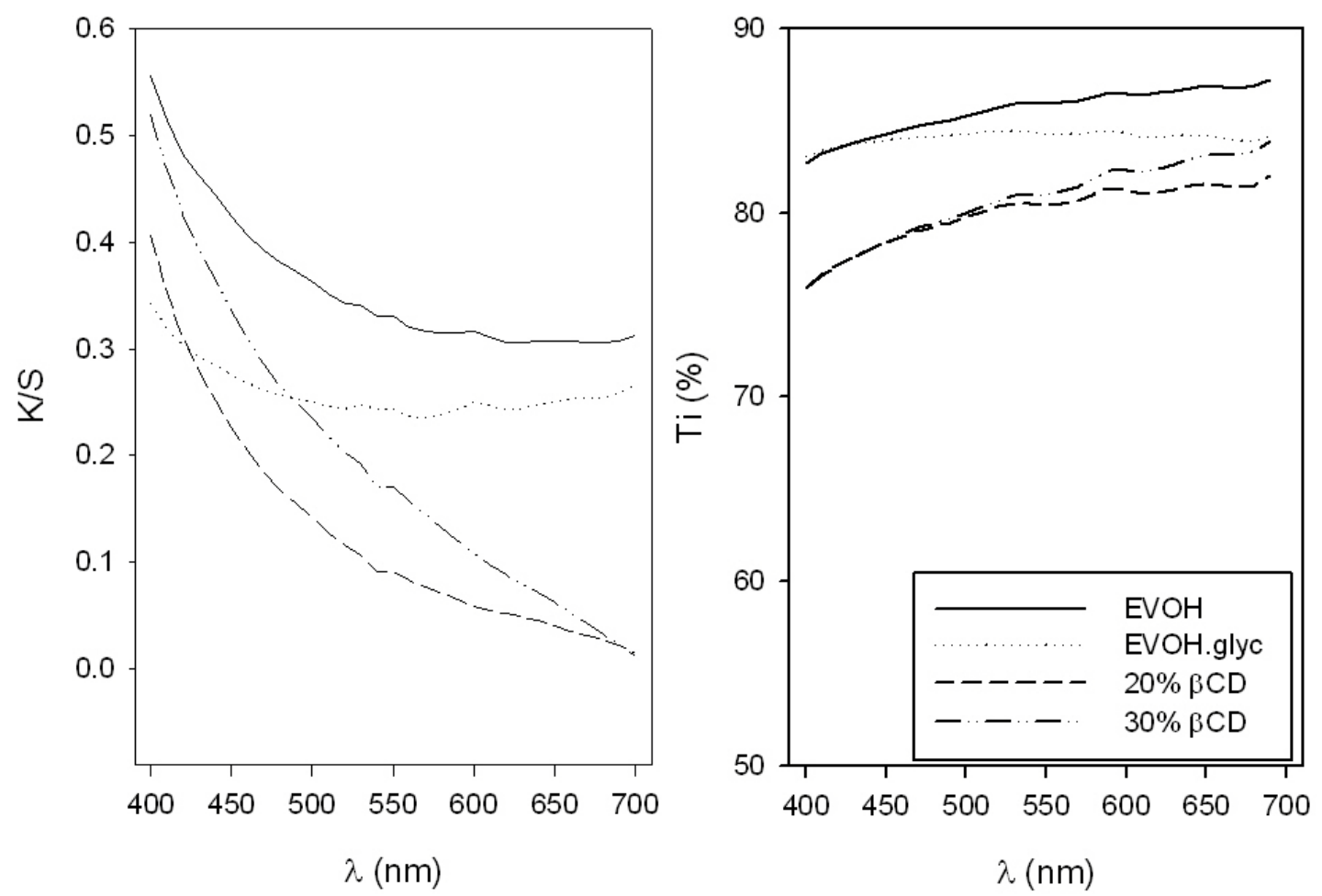

Figure 1. Values of the Kubelka-Munk transparency parameter (K/S) and of the internal transmittance (Ti) as a function of wavelength. 


\subsection{Cholesterol scavenger results}

283 Firstly, the cholesterol concentration in milk was determined by GC following the method described by Fletouris (Fletouris et al., 1998), using $5 \alpha$-cholestane as the internal standard. The extraction method was tested by measuring the cholesterol content of a known sample; the cholesterol was dissolved in ethanol and then diluted with distilled water to a final cholesterol concentration of $150 \mu \mathrm{g} / \mathrm{mL}$. The results showed the method to have good efficacy, with yields of $95.7 \pm 2.3 \%$. The tests carried out on the milk samples as received yielded concentrations of $151.5 \pm 4.3$ and $161.6 \pm 3.2$ $\mu \mathrm{g} / \mathrm{mL}$ for the pasteurized and the UHT milk samples, respectively, which are in agreement with data reported in the literature (Valenzuela et al., 2002, Sterna and Jemeljanovs, 2003).

For the first set of experiments was carried out at $4{ }^{\circ} \mathrm{C}$ with pasteurized milk, the results obtained after 2 and 7 days of exposure are presented in Table 2. At day two, the milk sample exposed to a film without $\beta C D$ presented a slight reduction that cannot be considered significantly different from the cholesterol level of the control. In contrast, the concentration of cholesterol in the milk exposed to $\beta \mathrm{CD}$ containing EVOH samples decreased significantly $(\mathrm{p}<0.05)$ with respect to the control sample, although no effect of $\beta C D$ concentration could be observed. Similar results were obtained at 7 days, when the lowest cholesterol concentration values were obtained for the samples exposed to the films containing $\beta C D$, although the reduction in cholesterol concentration was only significant for the sample with the highest $\beta C D$ content. However, the most noticeable variation was that observed with storage time. The presence of cholesterol was significantly lower in all the samples, with the largest variations being found in the control samples. This decrease cannot be attributed to the presence of the EVOH films or to the incorporation of the $\beta \mathrm{CD}$. A decrease in the cholesterol concentration in milk during storage can be due to internal milk reactions caused by lactic bacteria of a proteolitic and lipolitic nature (Varnam and Sutherland, 1995). The reason for the smaller reduction measured in the samples with $\beta C D$ could be that complexation within

311 the active matrix has a protective effect on the cholesterol molecules. Feigenbaum et al.

312 (1998) described the protective effect of scalping on unstable aroma components in 313 orange juice. 
Table 2. Cholesterol concentration (mg/L) and \% of reduction of cholesterol at days 2 and 7 in pasteurized milk exposed to EVOH materials at $4{ }^{\circ} \mathrm{C}$.

\begin{tabular}{c|cc|cc}
\hline \multirow{2}{*}{ Cholesterol } & Reduction (\%) & Cholesterol & Reduction (\%) \\
\hline Milk & $151.3 \pm 7.2 \mathrm{a}, \mathrm{x}$ & & $120.5 \pm 5.6 \mathrm{a}, \mathrm{y}$ & \\
Blank & $145.6 \pm 7.0 \mathrm{a}, \mathrm{x}$ & 3.8 & $115.7 \pm 5.4 \mathrm{ab}, \mathrm{y}$ & 4.0 \\
$20 \% \beta \mathrm{CD}$ & $130.9 \pm 1.4 \mathrm{~b}, \mathrm{x}$ & 13.5 & $113.5 \pm 4.2 \mathrm{ab}, \mathrm{y}$ & 6.2 \\
$30 \% \beta \mathrm{CD}$ & $125.5 \pm 6.9 \mathrm{~b}, \mathrm{x}$ & 17.1 & $110.5 \pm 2.1 \mathrm{~b}, \mathrm{y}$ & 8.3 \\
\hline
\end{tabular}

A second set of experiments was carried out with UHT milk at $23{ }^{\circ} \mathrm{C}$. In this assay, the sample with $\mathrm{EVOH}$ films without $\beta \mathrm{CD}$ was not included since no scavenging effect by the pure polymer had been observed. As can be seen in Table 3, a significant reduction in cholesterol levels was measured for the samples with $\beta C D$ after two days of storage. No differences were observed between samples with $20 \%$ and $30 \%$ of $\beta C D$. When compared with the values shown in Table 2, the active films presented similar efficiency at the two storage temperatures, with slightly higher values for the pasteurized milk stored at $4^{\circ} \mathrm{C}$.

The behavior of the UHT milk samples was similar on day 7. The presence of the active films resulted in a significant reduction in cholesterol concentration. The cholesterol scavenging activity increased with the concentration of $\beta C D$ in the film samples. In this test with UHT milk, no reduction of cholesterol with time was observed in the control sample, indicating that the handling of samples in aseptic conditions together with the use of UHT milk reduced the potential influence of lipolitic microorganisms on the results. After a week of exposure, the $\mathrm{EVOH}$ material containing 30\% $\beta \mathrm{CD}$ had adsorbed nearly $23 \%$ of the initial cholesterol content. As mentioned in the introduction, 1:1, $1: 2$ and 1:3 cholesterol/ $\beta C D$ inclusion complexes have been reported in the literature. In this work, the low mobility of the cyclodextrin molecules within the matrix should hinder the formation of inclusion complexes other than 1:1 cholesterol/ $\beta C D$. Most probably, the alquilic chain of the cholesterol molecule is trapped in the $\beta C D$ cavity (see dimensions in Table 1). Taking this hypothesis into account and considering 
that after the washing steps the film samples contained $12 \%$ and $18 \%$ of $\beta C D$, the percentages of $\mathrm{CD}$ molecules involved in cholesterol scavenging after 7 days were $15.5 \%$ and $15.7 \%$ for the $20 \% \beta C D$ and $30 \% \beta C D$ samples respectively. A reduction in film thickness could accelerate the diffusion of the large cholesterol molecules and increase the scavenging efficiency of the films. No significant differences were observed between the samples containing 20\% $\beta C D$ and 30\% $\beta C D$.

Table 3. Cholesterol concentration (mg/L) and \% of reduction of cholesterol at days 2 and 7 in UHT milk exposed to EVOH materials at $23^{\circ} \mathrm{C}$.

\begin{tabular}{c|cccc}
\hline & \multicolumn{2}{c}{ Day 2 } & \multicolumn{2}{c}{ Day 7 } \\
& Cholesterol & Reduction (\%) & Cholesterol & Reduction (\%) \\
\hline Milk & $161.4 \pm 16.4 \mathrm{a}, \mathrm{x}$ & & $152.5 \pm 4.7 \mathrm{a}, \mathrm{x}$ & \\
$20 \% \beta \mathrm{CD}$ & $142.8 \pm 2.2 \mathrm{ab}, \mathrm{x}$ & 11.5 & $129.2 \pm 1.2 \mathrm{~b}, \mathrm{x}$ & 15.3 \\
$30 \% \beta \mathrm{CD}$ & $140.1 \pm 3.8 \mathrm{~b}, \mathrm{x}$ & 13.2 & $117.2 \pm 5.1 \mathrm{c}, \mathrm{y}$ & 23.2 \\
\hline
\end{tabular}

352

353

354

355

356

357

358

359

360

361

362

363

364

365

366

367

368

369

370

371

a, b, c... indicate significant differences in the values of different samples on the same day. $\mathrm{x}, \mathrm{y} . .$. indicate significant differences in the values of the same sample on different days.

\subsection{Monitoring peanuts oxidative products}

Hexanal is one of the principal volatile compounds formed during lipid peroxidation and its concentration in the package headspace is usually monitored as an index of lipid deterioration. It has been described as the main oxidation product formed from linoleic acid, a polyunsaturated fatty acid present in peanuts, and it is chosen as an indicating chemical for the oxidation of peanuts (Han et al., 2008). In the present study, hexanal was the most important volatile component identified by GC-MS in the package headspace over the 10 weeks of storage.

A previous study of the food aroma retention capacity of $\beta C D$ (free and incorporated into EVOH films) showed preferential sorption of compounds with apolar molecules (Lopez de Dicastillo et al., 2010). In that study, exposing a $\beta C D$ containing film to a hydroalcoholic solution resulted in n-hexanal retention of up to $40 \%$. The formation of $\beta C D$ inclusion complexes with apolar 'guest' molecules has been described earlier (Goubet et al., 1998; Szente and Szejtli, 2004). 
372 Four sets of samples were studied: peanuts (peanuts), peanuts with an EVOH film

373 without $\beta C D$ to measure the scalping effect of the pure copolymer (blank), peanuts with

374 a film sample containing $20 \%$ of $\beta C D(20 \% \beta C D)$ and peanuts with a film sample 375 containing $30 \%$ of $\beta C D(30 \% \beta C D)$. Figure 2 shows the evolution of the hexanal 376 concentration in the bag headspace of all the samples over the storage time. As can be 377 seen, the amount of hexanal in the internal atmosphere of the peanuts samples increased 378 rapidly and steadily with time till week eight. From that moment, the concentration of 379 hexanal in the packaged headspace remained constant. This could be caused by a 380 reduction in the release of hexanal and/or because a partition equilibrium between the 381 fried peanuts and the internal atmosphere had been reached. The blank samples presented a similar profile. However, the hexanal concentration in the samples containing $\beta C D$ increased at a significantly slower pace $(\mathrm{p}<0.05)$ than in the peanuts and blank samples. This difference can be attributed to the presence of $\beta C D$ and the formation of inclusion complexes, since the sample with pure EVOH (blank) did not present significant differences with respect to the peanuts sample. During the first two weeks of storage, the concentration of hexanal in the samples with $\beta C D$ was half that of the control samples. This reduction continued up to week 5, when the concentration of hexanal in all the samples increased to similar values. At weeks 9 and 10 no significant differences between samples were observed, possibly because the scavenging capacity of the films had been exhausted.

Additionally, more volatile compounds in the headspace were identified as pentanal, heptanal, 2-heptenal, octanal and 2-octenal. These could be the result of degradation of the vegetable oils used in the frying process. Chung et al. (1993) and Guillen and Ruiz (2005) reported that the main aldehydes generated by oxidation of frying oils were 2alkenals and n-alkanals. The evolution of these aldehydes is shown in Figure 3. As expected, the concentration of all five compounds increased over the storage time in all the samples. Also, in all the cases the compound formation slope was higher after the 400 fourth week. With respect to the effect of the materials, the results showed that those containing $\beta C D$ presented the expected scavenging activity, significantly reducing the concentration of all aldehydes after the first week. At the tenth week, the reductions on pentanal, heptanal and 2-octenal concentrations were 28, 33 and 56\% in the case of the films with 20\% $\beta C D$, and 21, 22 and $48 \%$ in the case of films with 30\% $\beta C D$, respectively, being the effect of $\beta C D$ concentration in the film not statistically 
406

407

408

409

410

significant on the concentration of aldehydes measured at the package headspace. This result might be a consequence of partition equilibria that occur in the active film/food/headspace system and that can minimize the effect of scavenging on the measured concentrations at the headspace.

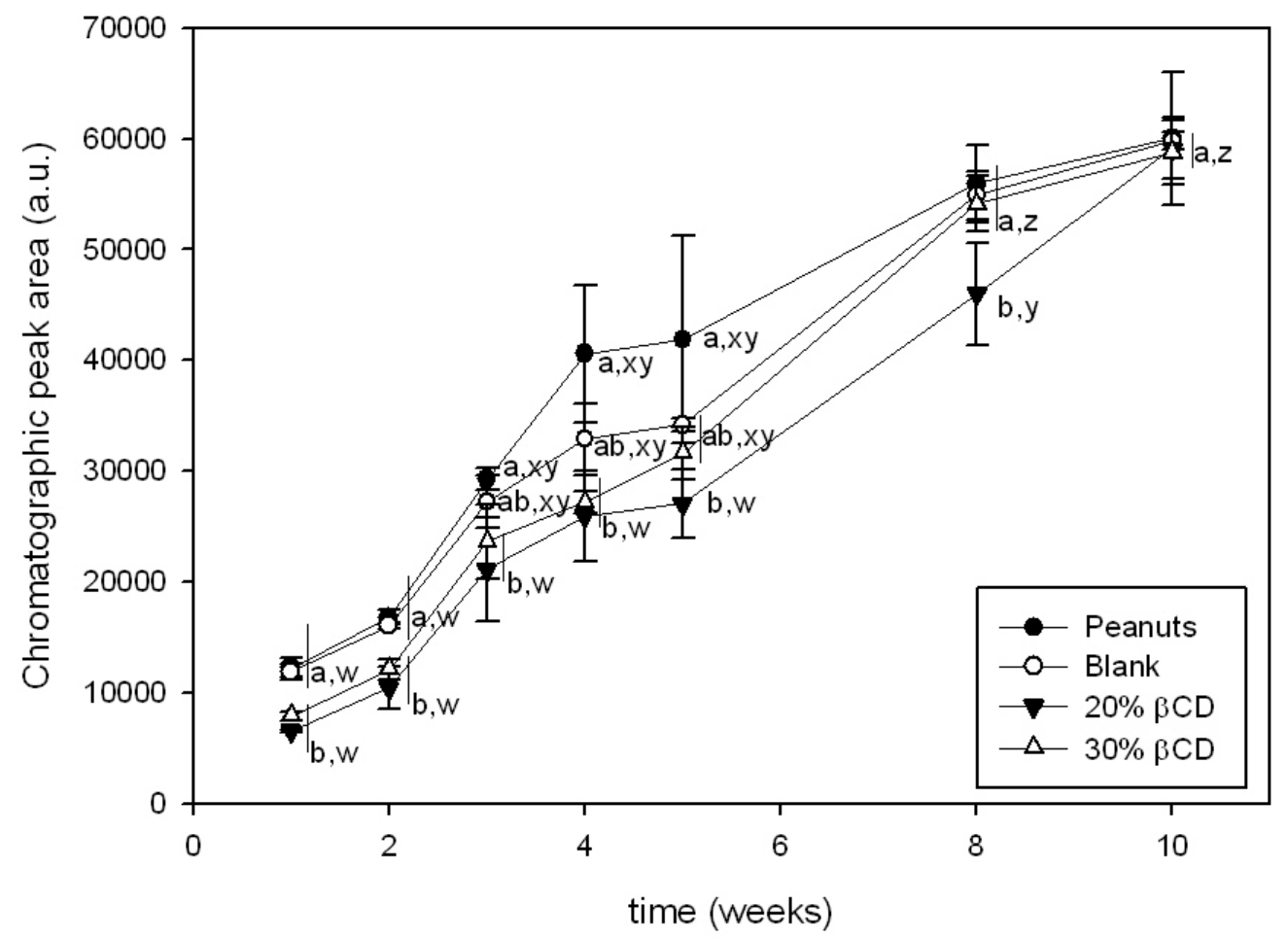

411

412

413

414

415

416

417

418 These results prove that these EVOH films presented the expected activity in reducing

419 the concentration of apolar compounds in the package headspace. Since the blank 420 samples did not show any noticeable scalping activity, the formation of inclusion 421 complexes with the $\beta C D$ molecules appears to be the most plausible action mechanism.

422 As can be seen in Table 1, all mentioned aldehydes present a maximum diameter below 423 that of the $\beta C D$ cavity.
Figure 2. Hexanal concentration evolution over storage time. a, b, c... indicate significant differences in the values of different samples on the same day. $\mathrm{x}, \mathrm{y} . .$. indicate significant differences in the values of the same sample on different days. 

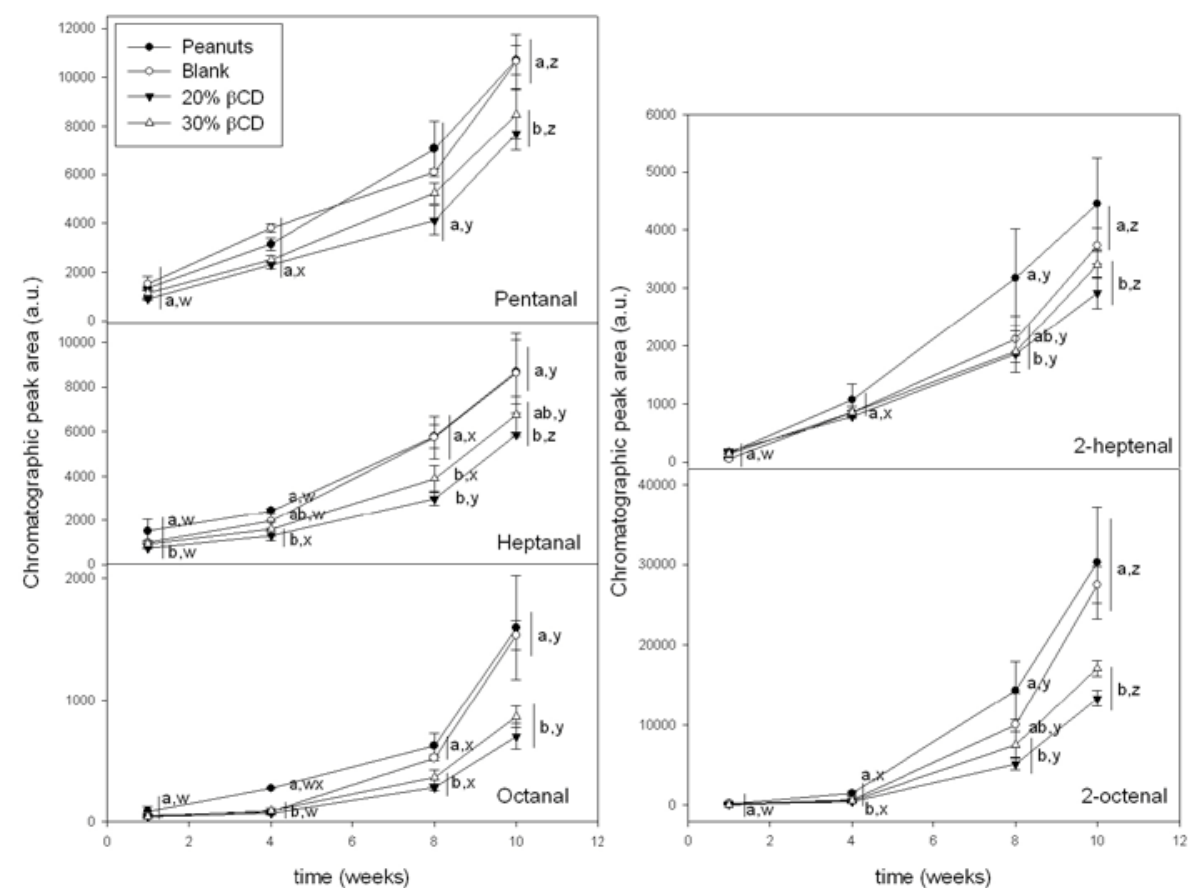

Figure 3. Concentration evolution of pentanal, heptanal, 2-heptenal, octanal and 2octenal, over storage time. a, b, c... indicate significant differences in the values of different samples on the same day. $\mathrm{x}, \mathrm{y} . .$. indicate significant differences in the values of the same sample on different days.

To measure the actual amount of aldehydes retained by the film samples at the end of the storage period, the film was analyzed with a thermal desorber coupled to a GC. Unfortunately, separation of the different aldehydes could not be achieved and the chromatogram showed a wide peak. Since the calibration factors of the compounds were similar, with differences between constant values below $10 \%$ and molecular weights within a 10\% range, hexanal (the main compound) was considered the only aldehyde present in the film. The results showed that the blank film retained $0.37 \pm 0.10$ mg of hexanal per $g$ of polymer. The $20 \% \beta C D$ and the $30 \% \beta C D$ samples retained significantly higher amounts: $12.3 \pm 0.3$ and $15.4 \pm 0.3 \mathrm{mg} / \mathrm{g}$. Taking into consideration the actual $\beta C D$ concentrations in these films (10\% and 18\%) and the formation of $1 / 1$ aldehyde/ $\beta C D$ inclusion complexes, the percentage of cyclooligosaccharides involved in the scavenging processes were $115 \pm 23 \%$ and $97 \pm 15 \%$ for the $20 \%$ CD and $30 \%$ CD samples respectively. This result confirmed that the cyclodextrins were successfully incorporated into the EVOH films, with the internal cavity available for the retention of apolar organic compounds and that the films with 30\% CD retained higher amounts of aldehydes than those containing $20 \%$ even though it was not noticeable in the measured aldehyde concentrations in the headspace. The high polarity of the EVOH polymer 
segments appeared to interact only with the polar external surface of the

449 oligosaccharides. The smaller molecular size of these aldehydes (see Table 1) compared 450 to the cholesterol molecules increased the availability of $\beta C D$ for the formation of 451 inclusion complexes.

452

\section{Conclusions}

454

455

This study explored the capacity of EVOH films containing $\beta$-cyclodextrins to retain undesirable substances present in food or in the surrounding headspace. The films containing 20 and $30 \%$ of $\beta C D$ successfully retained cholesterol from pasteurized and UHT milk at 4 and $23^{\circ} \mathrm{C}$, respectively. To check their applicability to scavenging oxidative byproducts, these films were also tested with fried peanuts. As expected, the inclusion of $\beta \mathrm{CD}$ in the $\mathrm{EVOH}$ films resulted in a lower aldehyde concentration in the package headspace.

462

Similar applications of EVOH- $\beta C D$ films can be derived to retain undesired apolar compounds. Other potential applications could be to reduce migration by retaining apolar migrants within the film structure, or to incorporate active agents or functional components into the film in the form of inclusion complexes which would protect them during package manufacture and then release them into the food product.

\section{Acknowledgements}

470

The authors are grateful for the financial support of the Spanish Ministry of Science and Innovation, projects AGL2006-02176, AGL2009-08776 and Fun-C-Food CSD200700063, and of the C. L-d-D fellowship (FPU program). Mary Georgina Hardinge provided assistance with the English language text.

\section{References}

478 Almenar, E., Auras, R., Rubino, M., \& Harte, B. (2007). A new technique to prevent the main post harvest diseases in berries during storage: Inclusion complexes betacyclodextrin-hexanal. International Journal of Food Microbiology, 118, 164-172. 
482 Astray, G., Gonzalez-Barreiro, C., Mejuto, J.C., Rial-Otero, R., \& Simal-Gándara, J. 483 (2009). A review on the use of cyclodextrins in foods. Food Hydrocolloids, 23, 16314841640.

485

486 Burroni, L.V., Grosso, N.R., \& Gurzman, C.A. (1997). Principal volatile components of 487 raw, roasted and fried Argentinean peanut flavors. Journal of Agricultural and Food 488 Chemistry, 45, 3190-3192.

489

490 Charles, F., Sanchez, J., \& Gontard, N. (2006). Absorption kinetics of oxygen and 491 carbon dioxide scavengers as part of active modified atmosphere packaging. Journal of Food Engineering, 72, 1-7.

493

494

495

Chung, T. Y., Eiserich, J.P., \& Shibamoto, T. (1993). Volatile compounds identified in 496 headspace samples of peanut oil heated under temperatures ranging from 50 to $200{ }^{\circ} \mathrm{C}$. Journal of Agricultural and Food Chemistry, 41, 1467-1470.

498

499

Cravotto, G., Binello, A., Baranelli, E., Carrazo, P., \& Trotta, F. (2006). Cyclodextrins 500 as food additives and in food processing. Current Nutrition \& Food Science, 2, 343501 350.

502

503 Fabra, M.J., Talens, P., \& Chiralt, A. (2010). Influence of calcium on tensile, optical 504 and water vapour permeability properties of sodium caseinate edible films. Journal of 505 Food Engineering, 96, 356-364.

506

Feigenbaum, A.; Lebossé, R., \& Ducruet, V. Polypropylene as active packaging 508 material for aroma sorption from model orange juice. In Food Flavors: Formation, Analysis, and Packaging Influences, No. 40 in Series: Developments in Food Science;

510 Contis, E. T., Ho, C. T., Mussinan, C. J., Parliment, T. H., Shahidi, F., Spanier, A. M., 511 Eds.; Elsevier: Amsterdam, The Netherlands, 1998; pp 743-751

513 Fletouris, D.J., Botsoglou, N.A., Psomas, I.E., \& Mantis, A.I. (1998). Rapid 514 Determination of Cholesterol in Milk and Milk Products by Direct Saponification and 515 Capillary Gas Chromatography. Journal of Dairy Science, 81, 2833-2840. 
517 Flores, S., Conte, A., Campos, C., Gerschenson, L., \& Del Nobile, M. (2007). Mass

518 transport properties of tapioca-based active edible films. Journal of Food Engineering, $51981,580-586$.

520

521 Goubet, I., Le Quere, J.L., \& Voilley, A.J. (1998). Retention of aroma compounds by

522 carbohydrates : Influence of Their Physicochemical Characteristics and of Their

523 Physical State. A Review. Journal of Agricultural and Food Chemistry, 46, 1981-1990.

525 Guillén, M.D., \& Ruiz, A. (2005). Monitoring the oxidation of unsaturated oils and 526 formation of oxygenated aldehydes by proton NMR. European Journal of Lipid Science 527 and Technology, 107, 36-47.

Han, J.H., Hwang H.M., \& Krochta J.M. (2008). Coating of peanuts with edible whey protein film containing $\alpha$-tocopherol and ascorbyl palmitate. Journal of Food Science, 73, 349-355.

532

Hutchings, J.B. (1999). Food colour and appearance, 2nd edn, Kluwer Academic/Plenum Publishers, London.

López-Carballo, G., Cava, D., Lagarón, J.M., Catalá, R., \& Gavara, R. (2005). Characterization of the interaction between two food aroma components, $\alpha$-pinene and ethyl butyrate, and ethylene-vinyl alcohol copolymer (EVOH) packaging films as a function of environmental humidity. J. Agric. Food Chem., 53, 7212-7216.

López de Dicastillo, C., Gallur, M., Catalá, R., Gavara, R., \& Hernandez-Muñoz, P. (2010). Immobilization of $\beta$-cyclodextrin in ethylene-vinyl alcohol copolymer for active food packaging applications. Journal of Membrane Science, 353, 184-191.

545 López-Rubio, A., Almenar, E., Hernandez-Muñoz, P., Lagarón, J. M., Catalá, R., \& 546 Gavara, R. (2004). Overview of active polymer-based packaging technologies for food applications. Food reviews international, 20, 357-387. 
549 Schroder, B.G., \& Baer, R.J. (1990). Utilization of cholesterol-reduced milk fat in fluid 550 milks. Food Technology, 44, 145-150.

551

552 Sterna, V., \& Jemeljanovs, A. (2003). Comparison of fatty acids and cholesterol content

553 in the milk of Latvian cows. Veterinarija ir Zootechnika, 22, 95-98.

554

555 Szejtli, J. (1982). Cyclodextrin in Food, cosmetics and toiletries. Starch, 34, 379-385.

556

557 Szente, L., \& Szejtli, J. (2004). Cyclodextrins as food ingredients. Trends in Food

558 Science\&Technology, 15, 137-142.

559

560 Valenzuela, A., Sanhueza, J., \& Nieto, S. (2002). Cholesterol oxides (oxisterols):

561 factors conditioning their formation, biological effects and content in foods. Revista

562 Chilena de Nutrición, 29, 116-124.

563

564 Varnam, A.H. \& Sutherland, J.P. (1995). Leche y productos lácteos. Tecnología, 565 química y microbiología. Ed. Acribia, S.A. Zaragoza.

566

567 Wambura, P., \& Yang, W.W. (2010). Ultrasonication and edible coating effects on lipid

568 oxidation of roasted peanuts. Food Bioprocess Technology, 3, 620-628.

569

570 Williams, J.P., Duncan, S.E., Williams, R.C., Mallikarjunan, K., Eigel III, W.N., \& 571 O'Keefe, S.F. (2006). Flavors fade in peanuts during short-term storage. Journal of 572 Food Science, 71, 265-269.

573

574 Yamamoto, S., Kurihara, H., Mutoh, T., Xing X., \& Unno, H. (2005). Cholesterol 575 recovery from inclusion complex of $\beta$-cyclodextin and cholesterol by aeration at 576 elevated temperatures. Biochemical Engineering Journal, 22, 197-205. 